\title{
Human Aspects in Manufacturing Process Management
}

\author{
Manuel Geyer and Stefan Linner \\ Tecnomatix GmbH, Richard-Reitzner-Allee 8, D-85540 Haar bei Muenchen, Germany. \\ Email: manuel.geyer@tecnomatix.com
}

\begin{abstract}
The globalisation of world economy, constantly rising cost pressure in international competition and ever shorter product life cycles create new challenges for production planning. The concept of Manufacturing Process Management (MPM) provides an integrated working environment for production planning and a comprehensive platform to optimise production planning throughout the extended enterprise. The core of the concept is a database hosting a process model that describes manufacturing operations as well as required resources and affected product components. Various planning tools are connected to this database. Ergonomically safe workplaces can be defined using an integrated 3D human model. Ergonomic standards and best practices for manual working operations can be defined and implemented in a very effective way. Hence the planning of production facilities can be done faster with higher quality.
\end{abstract}

Key words: Production planning, Digital factory, MPM, Ergonomics, Human model, Material flow simulation

\section{CHALLENGES FOR PRODUCTION PLANNING}

The environment for production planning has become more and more complex. High quality standards and the cost pressure in today's global economy require high quality planning results. At the same time shortening product life cycles, the need to reduce time-to-market and time-to-volume as well as trends like build-to-order put tremendous pressure on the planning.

To respond to such challenges, planning has to start earlier and the planning process itself needs to get more efficient. Starting earlier means, that 
the product design is still 'unstable' and the planners need to handle many product changes that complicate their planning work. Simultaneous engineering creates the need for improved collaboration and communication both within planning teams as well as with other disciplines within a company or even the supply chain. On top of all that globalisation changes the way how companies operate and creates new challenges like working in geographically distributed teams, transferring proven processes from one plant to another, standardising processes and resources.

\section{MANUFACTURING PROCESS MANAGEMENT}

Manufacturing Process Management (MPM) of Tecnomatix offers a business strategy for the collaborative development and optimisation of manufacturing processes across the extended enterprise. MPM allows multiusers at multi-sites to collaborate as one single enterprise throughout the entire development of a manufacturing process. MPM leverages specific technologies and methodologies to create a collaborative environment for authoring, simulating and managing manufacturing processes.

MPM addresses the area of manufacturing that has historically been the most neglected area of the industrial process - the actual planning and creation of the manufacturing process. While CAD and PDM address "what" products to manufacture, and MES (Manufacturing Execution Systems) and ERP (Enterprise Resource Planning) address "when" and "where", MPM addresses "how" (Figure 1).

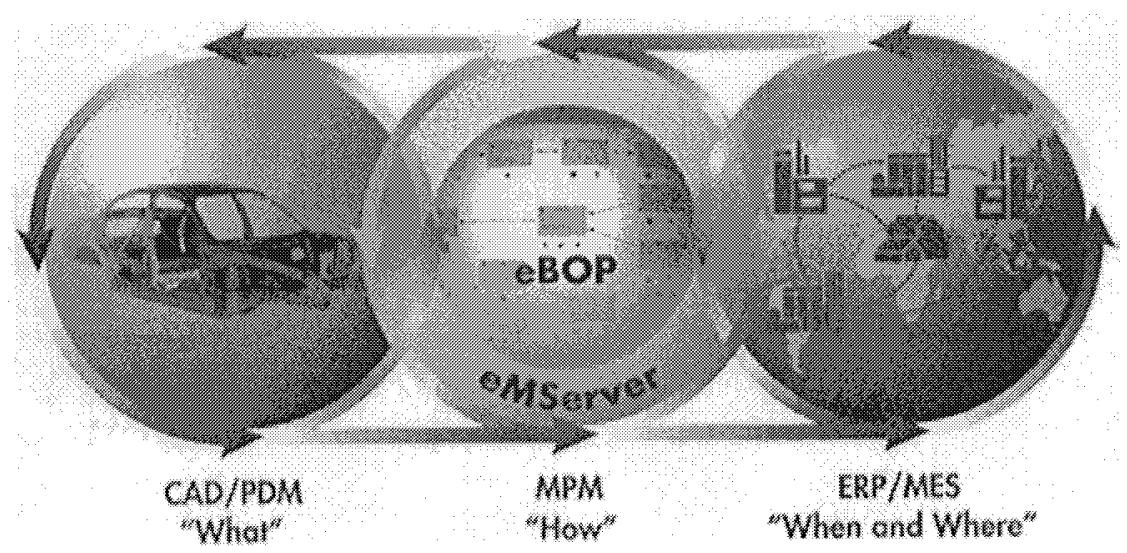

Figure 1. MPM integrates with CAD/PDM and ERP/MES systems (Source: LINNER, GEYER 2003, p. 38) 
MPM is a critical component of e-Manufacturing, a broader business strategy that addresses the full industrial process, from the initial concept of a new product until it is delivered to the customer. MPM enables manufacturers to define how the product is going to be manufactured and then to deliver these processes to the shop floor.

While the product design process defines an electronic bill of materials the "what" - MPM defines an electronic bill of processes (eBOP) - the "how." This information is stored on a server that allows easy access and management of data throughout the enterprise. MPM contributes a common language for the description of manufacturing processes and offers a collaborative environment that facilitates the exchange of information. The eBOP serves both as a clear and defined way of how to describe the manufacturing process and as an information carrier that allows for packaging all information about a process or a manufacturing line in order to send it to someone else.

The concept is realised through a database hosting a process model that describes manufacturing operations as well as required resources and affected product components. Various planning tools are connected to this database - spanning everything from digital mock-up analysis, to defining the production steps, optimising the workplaces with a human model and creating documentation (Figure 2).

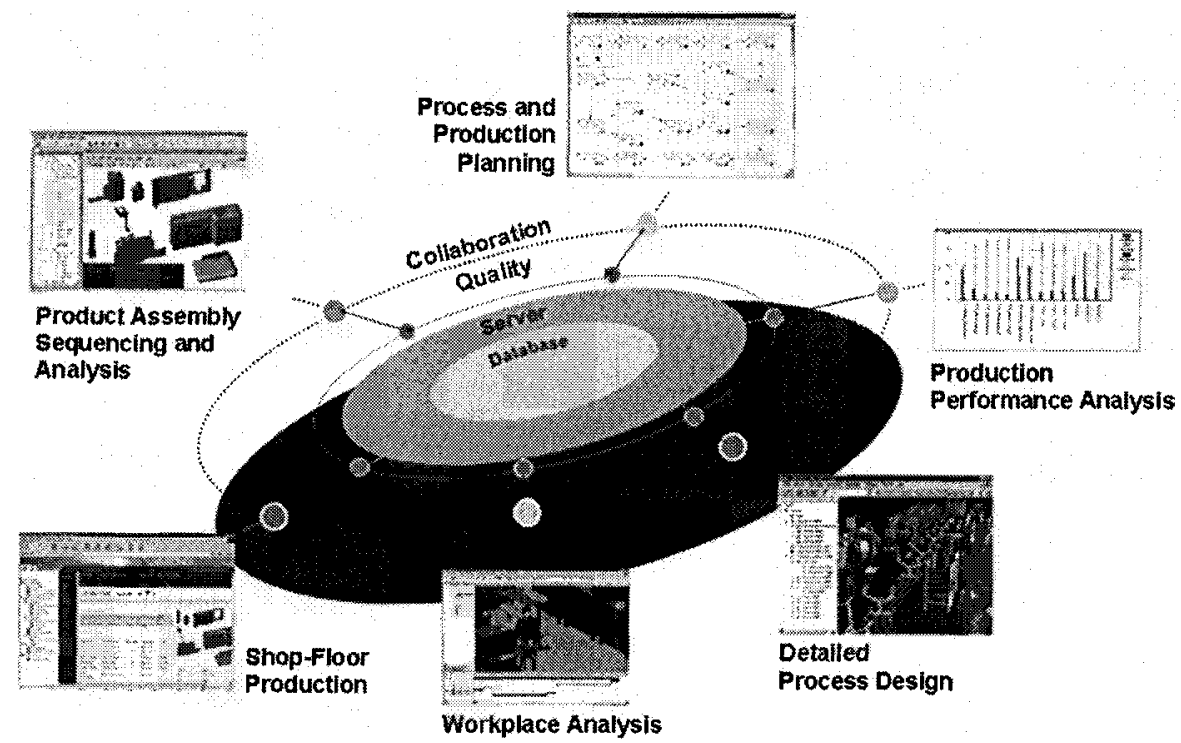

Figure 2. End-to-end Manufacturing Process Management 


\section{HUMAN ASPECTS IN PRODUCT DESIGN}

The design of the product itself obviously has a large impact on the required manufacturing processes. In the early stages of product design, the product is only available as a virtual CAD model, so a virtual environment for simulating the manufacturing aspects of the product design is necessary.

Verifying the manufacturing aspects of the product requires sound domain knowledge and experience and thus must be done by manufacturing planners. The 3D software therefore is specifically tailored to the needs of planners. In this virtual environment the planner will simulate the future assembly sequences and processes to find out problematic areas and to enable with his feedback to the designer an improvement of the product.

Typically used methods are simulation of the assembly paths of the parts, attaching a human hand or the high-end human model Ramsis (Figure 3). The checks in many cases will also include the future production equipment. This simultaneous engineering process enables a cost-effective, ergonomically safe and high-quality manufacturing process.
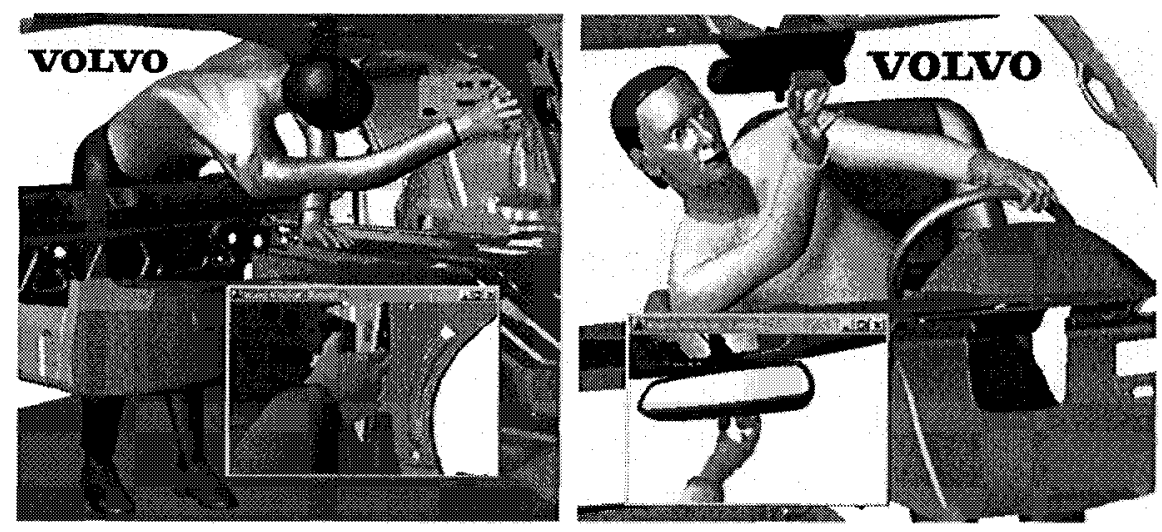

Figure 3. Ergonomic studies of assembly tasks using the 3D human model (pictures provided by Volvo Corporation, Sweden)

In complex products (cars, aircrafts) the planner has to perform a high number of assembly and maintenance studies. The studies can be saved in a structured way in the database for easy retrieval after changes of the product design, for detailing in a later stage of planning and for reuse in future planning projects. 


\section{HUMAN ASPECTS IN WORKPLACE DESIGN}

After rough planning of the layout structure and material flow the details of the workplaces are planned. Optimising manual workplaces and processes is usually driven by the need to minimise production costs. However it is clear, that skilled, healthy and motivated employees are representing a high value for the enterprise. Thus ergonomics and human simulation is a key point in MPM.

As described before, the human model is integral part of the 3D-planning environment (Figure 4). The user loads the human model into his current planning environment to evaluate the workplace configuration according to several ergonomic analysis methods. Most data (e.g. layout configuration, operation plans) required to perform a human simulation is already present on the server. This greatly improves the acceptance of the planners in performing an ergonomic evaluation.

In addition to the standard methods of ergonomic analysis (NIOSH, OWAS, Burandt-Schultetus, Rula) typically various company- and countryspecific ergonomic standards are used. A key point for acceptance of such a tool is the ability to customise the relevant methods with low effort to the regulations of the local production site.

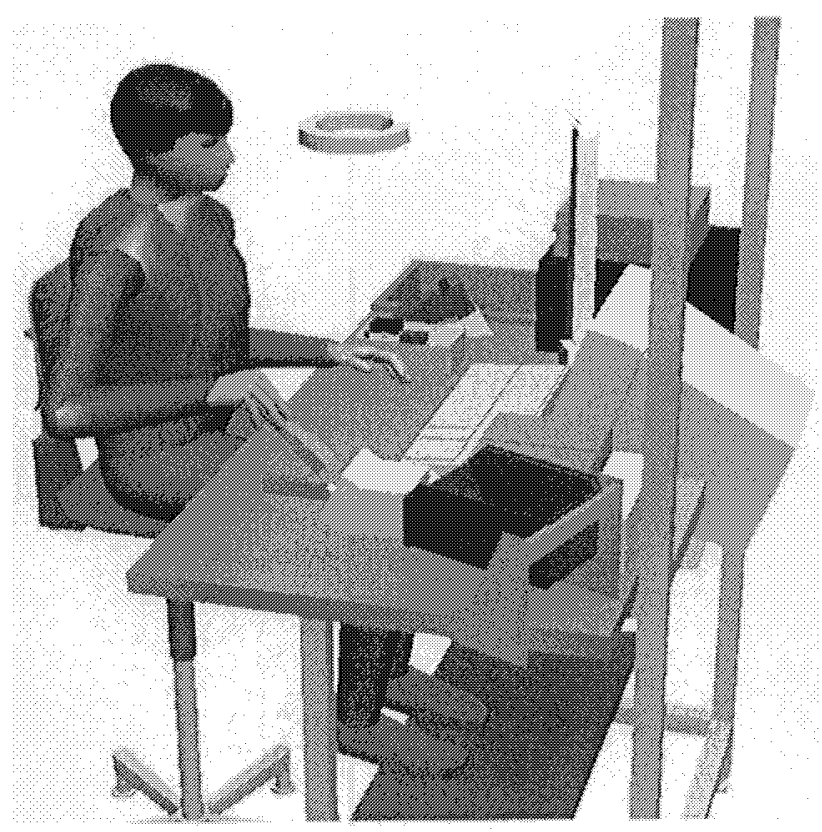

Figure 4. Example: Workplace design using the human model 


\section{HUMAN ASPECTS AND MATERIAL FLOW SIMULATION}

While the 3D simulation with human model mainly applies to analysing and optimising the ergonomic quality and cycle times of individual workplaces, the interaction and performance of the entire production is today analysed and optimised using material flow simulation.

This can also take into consideration aspects of human labour, such as stress, fatigue, learning and unlearning phases, pauses, shift cycles and the qualification of the worker. These aspects can thus be verified early in the planning process.

\section{IMPLEMENTATION ON THE SHOPFLOOR}

Finally MPM will ensure the implementation of the optimised work practices and workplaces. Various reports can be created that aggregate information out of the process database. From dimensioned 3D workplace drawings to electronic work instructions all necessary data can be generated and communicated.

\section{COLLABORATION AND COMMUNICATION}

Different levels of tools support different needs of collaboration and range from pure viewing to real collaborative process planning. They range from generating paper-based reports to online-access to the current planning database with standard Web-Browsers.

They may, for example, be used to deliver up-to-date information of the current planning state to management, project managers or other team members. In addition the ability to use a common language for describing production processes enables not only information, but a true collaboration: Typical scenario is a company that locally plans an assembly line for a new product, but does not have specialised knowledge on ergonomics. The local manufacturing engineer will do the layout of the line and conceptual design of equipment. He will now send all relevant information including the bill of materials, parts geometries, work content to be done, workplace configuration, as an $\mathrm{eBOP}$ to a corporate ergonomics competence centre in another location with the click of a button. The ergonomic expert will do the optimisation of the work system and send the data back to the local engineer (Figure 5). Of course, the same idea will work for the extended enterprise and external companies. 


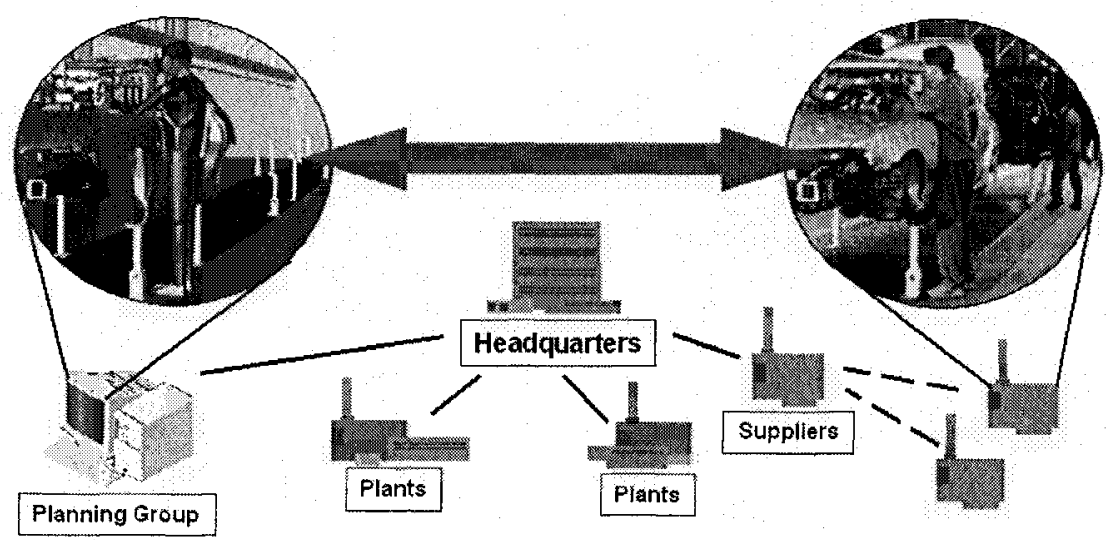

Figure 5. Communication of ergonomically safe procedures and workplaces (Source: LINNER, GEYER 2003, p. 41)

The integrated planning environment and the ability to store best practice processes in a database and reuse them for future projects reduces the planning effort significantly.

Another aspect of MPM is the possibility to define and enforce standards for the enterprise and to easily communicate them. Using the standard eBOP format a company may define libraries of predefined ergonomically safe and proven workplaces and work procedures for certain tasks (Figure 6). Web tools allow for making this information available to all relevant people in the entire organisation.

\section{SUMMARY}

Whereas both in product design (CAD/PDM) and production control (ERP, MES) fairly developed IT systems with a comparatively high degree of integration can be found, the IT landscape in production planning is primarily characterised by a large number of independent non-interacting software tools. This results in considerable overhead including multiple-entry of the same data, interface problems, etc.

The concept of Manufacturing Process Management (MPM) gives a solution by providing an integrated working environment for production planning and a comprehensive platform to optimise production planning throughout the extended enterprise.

Planning times can be shortened through usage of a common process database and concurrent engineering. The core of the concept is a database hosting a process model that describes manufacturing operations as well as 
required resources and affected product components. Various planning tools are connected to this database. Ergonomically safe workplaces can be defined using 3D technology using a human model. Additional human aspects will be considered using a material flow simulation.

Web-based collaboration tools enable planners to cooperate between several locations and to transfer proven production processes to other locations. The concept of a best practice database for processes and resources as well as integrated simulation tools help to increase productivity, maintain high quality standards and optimise product cost. Ergonomic best practices may be defined and implemented for the company, as well as for the suppliers.

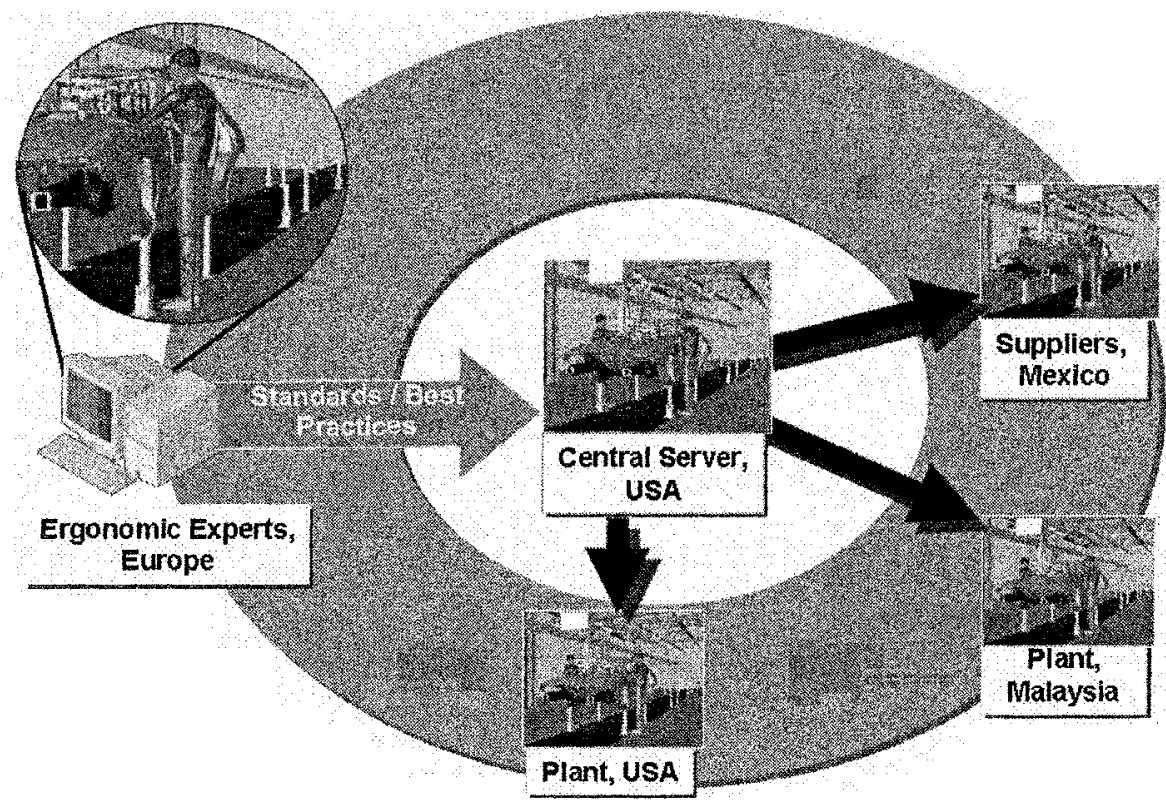

Figure 6. Standardisation and using best practices across the extended enterprise

\section{REFERENCES}

BAUR, Cornelius; KAAS, Hans-Werner; KASSNER, Sven et al.:

Profitable Wachstumsstrategien in der Automobilzulieferindustrie.

Düsseldorf: McKinsey \& Company, 2000. 
Ernst \& Young LLP (eds.):

Profile of Tomorrow's Automotive Supplier.

Atlanta, GA et al.: Ernst \& Young LLP, 1998..

http://www.autoindustria.com/encuentro/documentos/

automotive_supplier_capgemini.pdf, 29.07.03.

GEYER, Manuel:

Flexibles Planungssystem zur Berücksichtigung ergonomischer Aspekte bei der Produktund Arbeitssystemgestaltung.

Berlin, Heidelberg et. al.: Springer Verlag, 1997.

(iwb, Forschungsberichte Band 112)

JELTSCH, Michael; BAIER, Andreas; WAHRENDORFF, Matthias:

Auto 2010. Eine Expertenbefragung zur Zukunft der Automobilindustrie.

Sulzbach/Taunus: Accenture, 2001.

http:// automobile.karrierefuehrer.de/auto2010.pdf, 29.07.03.

LINNER, Stefan; GEYER, Manuel:

Human Aspects in Manufacturing Process Management.

In: Human Aspects in Production Management.

Eds.: ZÜLCH, Gert; STOWASSER, Sascha; JAGDEV, Harinder S.

Aachen: Shaker Verlag, 2003, pp. 37-43.

(esim - European Series in Industrial Management, Volume 5) 